\title{
Construção do Conhecimento Profissional do Professor de Computação pela pesquisa-ação
}

\author{
Adão Caron Cambraia ${ }^{1}$, Uianes Luiz Rockenbach Biondo² \\ ${ }^{1}$ Docente de Computação - Instituto Federal Farroupilha (IFFar) - Santo Augusto - RS \\ - Brasil \\ ${ }^{2}$ Acadêmico de Licenciatura em Computação - Instituto Federal Farroupilha (IFFar) - \\ Bolsista PIBIC (CNPq) - Santo Augusto - RS - Brasil \\ adao.cambraia@iffarroupilha.edu.br, biondouianes@gmail.com
}

\begin{abstract}
This article has as problematic to understand what constitutes the professional knowledge of the computer teacher trainers and in formation. To this end, we present an experience in a Degree in Computing, from the Federal Farroupilha Institute. Academics of the course developed a report about a practice developed in the curricular component of Computer Teaching Practice, where they narrate their perceptions about teaching with a Youth and Adult Education class, where they developed unplugged computing activities.
\end{abstract}

Resumo. Este artigo tem como problemática compreender como se constitui o conhecimento profissional do professor de computação formador e em formação. Para tanto, apresentamos uma experiência em um curso de Licenciatura em Computação, do Instituto Federal Farroupilha. Acadêmicos do curso desenvolveram um relato acerca de uma prática desenvolvida no componente curricular de Prática do Ensino da Computação, onde narram suas percepções sobre a docência com uma turma de Educação de Jovens e Adultos, onde desenvolveram atividades de computação desplugada.

É tônica na formação de professores de Computação a desarticulação entre conhecimentos científicos da área de atuação e conhecimentos específicos da Pedagogia. Esse não é um desafio exclusivo da Licenciatura em Computação (LC), mas também de outras licenciaturas, como por exemplo, em Geografia [Lopes 2009] e Pedagogia [Libâneo 2015]. Essa desarticulação se perpetua na formação de professores, principalmente, por falta de uma explicitação do conhecimento profissional docente, que é foco de estudo de autores, tais como: Gauthier 2013; Shulman 1986; 1987 e 2014. "Os defensores da reforma profissional baseiam seus argumentos na crença de que existe "uma base de conhecimento para o ensino" [Shulman 2014, p. 200], que de acordo com o autor "não é fixa e definitiva" [ibidem, p. 213], pois ao fazermos ${ }^{1}$ análises de nossas ações novas categorias serão produzidas. Avançar na pesquisa de um repertório de

\footnotetext{
${ }^{1}$ Em uma pesquisa-ação, o relatório leva em conta a participação direta do pesquisador. Isto significa que o uso da primeira pessoa do plural e do singular são mais usuais. Como o relatório é resultado de um trabalho colaborativo prevalece o uso da primeira pessoa do plural.
} 
conhecimentos sobre o ensino possibilita-nos enfrentar dois obstáculos que historicamente se interpuseram à ciência do educador: de um ofício sem saberes e de saberes sem ofício [Gauthier 2013].

O Conhecimento Profissional Docente foi categorizado por Lee Shulman (1987) em: Conhecimento do Conteúdo Temático do assunto; Conhecimento Pedagógico Geral; Conhecimento Curricular; Conhecimento Didático do Conteúdo; Conhecimento dos alunos e suas características; Conhecimento do contexto; Conhecimento dos fins, propósitos e valores educacionais e suas bases filosóficas e históricas. Neste texto, o foco de análise é o Conhecimento Didático do Conteúdo (CDC), que é produzido por meio do amalgama dos demais conhecimentos, e não da soma de diferentes conhecimentos [Leal Castro 2014] ${ }^{2}$. Em outras palavras, trata-se de um conhecimento dinâmico, em permanente construção, em que se pretende construir na interlocução produzida na Prática do Ensino da Computação IV (PEC IV) da LC do Instituto Federal de Educação, Ciência e Tecnologia Farroupilha - Campus Santo Augusto (Iffar). Assim, o objetivo é analisar indícios do desenvolvimento do CDC na formação de professores de Computação por meio da pesquisa-ação crítica e emancipatória [Carr e Kemmis 1988].

Como caminho metodológico, realizamos um estudo bibliográfico sobre o CDC, por meio do ensino de computação desplugada. Com essa fundamentação teórica, organizamos um projeto integrador, propondo estudos aos licenciandos, o planejamento e desenvolvimento de uma oficina com atividades desplugadas na turma do Programa Nacional de Integração da Educação Profissional com a Educação Básica na Modalidade de Educação de Jovens e Adultos - PROEJA ${ }^{3}$ do Iffar (mesmo Campus da Licenciatura em análise), composta por nove alunos ${ }^{4}$. Os dados de análise foram produzidos na PEC IV: Relatório Final organizado por cinco licenciandos em computação sobre o planejamento e desenvolvimento de oficina com atividades desplugadas; as interações entre professor formador/licenciandos em sala de aula; respostas de questionário e transcrição de entrevistas com licenciandos e alunos do Proeja. Parte dos excertos foram retirados do Relatório Final (RF), assim, foram identificados como RF, pelo fato de que o relatório foi construído em grupo não sendo possível uma identificação individualizada. Os participantes da pesquisa foram identificados como Licenciando 1; Licenciando $2 ; \ldots \mathrm{n}$ e/ou aluno 1, aluno 2, ..,n, para garantir o sigilo e evitar constrangimentos. Os dados produzidos na interlocução entre professores formadores, licenciandos e alunos do Proeja são os materiais que possibilitaram a construção das categorias de análise.

\footnotetext{
${ }^{2} \mathrm{O}$ autor citado explica dois enfoques para o CDC: o integrador ou aditivo e o transformador. Ambos perpassam pela presença de pelo menos o conhecimento disciplinar, Didático e contextual. No entanto, o aditivo resulta da soma dos três conhecimentos para dar origem ao CDC. No enfoque transformador, o autor usa a metáfora da química para explicita-lo: o amalgama de Hidrogênio e Oxigênio resulta em H2O (um elemento novo com características bem diferentes dos que lhe deram origem). Assim, no enfoque transformador, foco deste estudo, o CDC é um saber diferenciado dos saberes necessários para sua constituição.

${ }^{3}$ A escolha da turma do Proeja foi pela facilidade de acesso a essa turma (as turmas têm aula no mesmo prédio) e a possibilidade em desenvolver as atividades no mesmo turno das aulas da licenciatura.

${ }^{4}$ No texto ao usar a nomenclatura alunos nos referimos aos alunos do Proeja.
} 
VIII Congresso Brasileiro de Informática na Educação (CBIE 2019)

Anais dos Workshops do VIII Congresso Brasileiro de Informática na Educação (WCBIE 2019)

Para a análise dos dados utilizamos a Análise Textual Discursiva - ATD [Moraes e Galiazzi 2013], que

[...] pode ser compreendida como um processo auto-organizado de construção de compreensão em que novos entendimentos emergem a partir de uma sequência recursiva de três componentes: a desconstrução dos textos do "corpus", a unitarização; o estabelecimento de relações entre os elementos unitários, a categorização; o captar o emergente em que a nova compreensão é comunicada e validada [Moraes e Galiazzi 2013, p. 12].

A nova compreensão que é comunicada e validada denomina-se metatexto, em que a linguagem escrita desempenha duas funções fundamentais: "A participação na produção de novas compreensões e de sua comunicação cada vez mais válida e consistente" [Moraes e Galiazzi 2013, p. 13].

No primeiro tópico, foi realizado um estudo para construir o entendimento da produção do CDC por meio da pesquisa-ação vivenciada na PEC IV, produzindo a categoria "pesquisa-ação na constituição do conhecimento didático do conteúdo". No segundo tópico, visamos explicitar as ações e reflexões, que nos levaram a novas compreensões do saber docente, principalmente, no que tange a produção do CDC, em que construímos a categoria "constituição do CDC: ações e reflexões no ensino da computação".

\section{Pesquisa-ação na constituição do conhecimento didático do conteúdo}

A PEC IV IV $^{5}$ foi constituída com a seleção e estudo de conteúdos da Ciência da Computação, seguido de planejamento, desenvolvimento das ações, resultando num processo de observação, análise e reflexão do professor formador sobre o material produzido pelos licenciandos à luz do CDC, em sucessivas espirais de investigação-ação crítica e emancipatória [Carr e Kemmis 1988], conforme Figura 1.

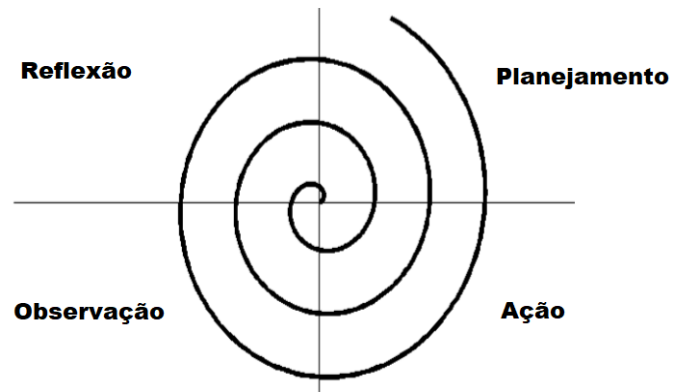

Figura 1. Espirais Reflexivas da pesquisa-ação. [Adaptado de: Carr e Kemmis 1988 p. 197]

A pesquisa-ação tem um duplo sentido: produção de conhecimento e transformação da prática. Assim, no planejamento do Projeto Integrador pensado coletivamente para a PEC IV foi proposto o desenvolvimento de oficinas sobre computação desplugada no $3^{\circ}$ ano do PROEJA do Iffar. Para isso, utilizamos como referência Bell, Witten e Fellows (2011) e França, Silva e Amaral (2012). Um dos

\footnotetext{
${ }^{5}$ A PEC IV é um componente curricular da Licenciatura em Computação para atender a Prática enquanto Componente Curricular, que deve possuir 400 horas distribuídas conforme Projeto Pedagógico construído pelo colegiado do Curso.
} 
VIII Congresso Brasileiro de Informática na Educação (CBIE 2019)

Anais dos Workshops do VIII Congresso Brasileiro de Informática na Educação (WCBIE 2019)

tópicos da ementa do componente curricular contempla "o ensino da computação e a Educação Tecnológica como conhecimento básico e fundamental”. As atividades planejadas foram adaptadas e transformadas para serem utilizadas no Proeja. A Licenciatura e o Proeja estão alocados no mesmo Campus, de modo que alguns alunos se conhecem, e, além disso, os licenciandos dialogaram com os professores de Educação Básica que atuam no Proeja para entender melhor a cultura dos alunos, o que proporcionou a criação de atividades contextualizadas com a realidade da turma. Conforme Padilha (2001, p. 30), "o ato de planejar é sempre processo de reflexão, de tomada de decisão sobre a ação, de previsão de necessidades e racionalização do emprego de meios necessários para a concretização de objetivos".

Durante o planejamento cada licenciando se comprometeu em organizar e coordenar uma ou mais ações para desenvolver com os alunos. Houve produção de novos diálogos que geraram outras reflexões. O tempo de intervenção e desenvolvimento da atividade, bem como, o objetivo e a contribuição de cada uma para construir o resultado almejado foram observados e registrados pelos licenciandos (esse material consta no Relatório Final) constituindo subsídios para novas reflexões.

A organização do trabalho durante a fase de planejamento consiste na disposição de um conjunto de tarefas que visam, por exemplo, a determinar os objetivos de aprendizagem, bem como priorizar e transformar os conteúdos em correspondência com os objetivos [Gauthier 2013, p. 198].

Vale lembrar que o livro CS Unpllugged foi explorado na disciplina de "Metodologia do Ensino da Computação I", o que propiciou aos licenciandos adaptarem as atividades de acordo com os objetivos e expressarem como o Licenciando 4 a compreensão da importância do "ensino da computação no Ensino Fundamental. Com essa metodologia não é preciso o uso de computadores para o ensino da computação". Além disso, "nos mostra que se pode ensinar computação de várias maneiras, facilitando o processo de aprendizagem dos alunos" (Licenciando 2). Assim, no contexto disciplinar também se produziu significados, ao vincular os conceitos disciplinares ao projeto integrador, possibilitando relações com a realidade complexa e proporcionando a concretização dos objetivos da disciplina e a construção de conhecimentos significativos.

A primeira fonte da base de conhecimento é o conhecimento do conteúdo conhecimento, compreensão, aptidão e disposição que devem ser adquiridos pelos alunos. Esse conhecimento repousa sobre duas fundações: a bibliografia e os estudos acumulados nas áreas do conhecimento, e a produção acadêmica histórica e filosófica sobre a natureza do conhecimento nesses campos do estudo [Shulman 2014, p. 207].

Então, partimos da premissa de que "um professor sabe alguma coisa não sabida por outrem, presumivelmente os alunos" [Shulman 2014, p. 205] e que o ensino conclui com uma "nova compreensão tanto do professor como do aluno" [ibidem, p. 205-206], professor e aluno aprendem no processo de elaboração do conhecimento por meio do projeto integrador.

O projeto integrador (planejado e desenvolvido pelos licenciandos) iniciou com a definição da seguinte problemática: "É possível ensinar computação na Educação Básica e proporcionar o desenvolvimento do raciocínio lógico?”. O objetivo é “aprender e desenvolver metodologias que possibilitem o ensino da computação na Educação Básica e o desenvolvimento do raciocínio lógico” (RF, p.17). Com essa definição, 
questionamos os Licenciandos: "Como vocês saberão se os alunos desenvolveram o raciocínio lógico?" (interação em sala de aula). Os alunos trouxeram muitas sugestões, tais como: questionários, provas e, por fim, a sugestão de aplicação de um jogo de raciocínio lógico, antes e depois das atividades, com marcação de tempo para saber se conseguem resolver o problema mais rápido, significando aprimoramento no raciocínio lógico ${ }^{6}$. Executamos o jogo, marcamos o tempo e achamos pertinente avaliar as atividades dessa forma para construir indícios sobre a contribuição ou não da inclusão do jogo como um desafio que potencializaria a aprendizagem. Ao aceitar o argumento e a proposta dos alunos percebemos que o desafio de pesquisa deixou os licenciandos mais interessados e comprometidos com o planejamento das atividades.

Conforme os futuros professores, as atividades poderiam ser desenvolvidas em qualquer sequência, pois o entendimento de uma não depende da outra. Então, salientaram que definir a sequência teve a finalidade de apresentar primeiro as atividades em que eles tinham mais segurança e domínio dos conteúdos. "As técnicas de ensino flexíveis e interativas não podem ser usadas quando não se entende do assunto a ser ensinado" [Shulman 2014, p. 221]. O que nos proporciona entender sobre a importância do Conhecimento do Conteúdo para o desenvolvimento de atividades interativas, que propiciem a elaboração de conhecimentos significativos e de forma interdisciplinar.

A interdisciplinaridade esteve presente na prática profissional. Ao questionar os licenciandos sobre a existência de um movimento interdisciplinar nas ações realizadas, o Licenciando 4 responde que percebe entre as disciplinas de "Programação, Didática, Metodologia e Redes" - fazendo relação às disciplinas do curso de LC. Assim, ao propor diálogos interdisciplinares na PEC IV, por meio do projeto integrador, o conhecimento disciplinar constitui-se imprescindível, pois ao conhecer com profundidade uma disciplina é possível identificar aproximações conceituais muitas vezes esquecidas do espaço da escola.

Além da interdisciplinaridade presente na formação de professores, as atividades planejadas visam o trabalho interdisciplinar na Educação Básica, como por exemplo, a atividade 6 - sobre algoritmos e programação de computadores - em que o aluno A explica para o aluno B como fazer um determinado desenho numa folha em branco (o aluno B não sabe qual é o desenho). Além de desenvolver conceitos de programação, construindo um desenho por meio de uma sequência de comandos, articula com Português, proporcionando o desenvolvimento da comunicação e expressão dos alunos.

Esta visão das fontes relacionadas ao conteúdo do conhecimento necessariamente implica que o professor deve ter não apenas profundidade de compreensão das matérias específicas que ensina, mas também uma educação humanista abrangente, que serve para enquadrar o já aprendido e facilitar a nova compreensão. [...] A maneira como essa compreensão é comunicada transmite aos alunos o que é essencial e o que é periférico na matéria [Shulman 2014, p. 208].

\footnotetext{
${ }^{6}$ Questionamos a forma escolhida pelos alunos por entendermos que a resolução mais rápida do jogo não significaria o desenvolvimento do raciocínio lógico. Em discussões argumentaram que "a criação do Desafio na atividade seria um estimulo para os alunos desenvolverem as atividades, o que seria mais importante do que "medir" o desenvolvimento do raciocínio lógico" (Licenciando 4 - interações em sala de aula).
} 
Segundo Lopes (2007), a passagem do conhecimento científico para o escolar é um processo de transformação. Dentre os conhecimentos escolares "não se incluem apenas conhecimentos científicos, mas todos os saberes que em dado momento histórico são entendidos como válidos e legítimos" [Lopes 2007, p. 196]. Segundo a autora, a transformação não é somente a 'transposição', que passa a ideia de transferência do conhecimento de um lugar para outro. Para a autora citada, a transformação é 'mediação didática'. Assim, as concepções expressas trazem indícios de que o conhecimento científico (que é fundamental) precisa ser transformado pela ação do professor, para que tenha significado. As atividades desplugadas são uma forma de transformação de conceitos da ciência da computação em conhecimento computacional escolar.

O processo de ensino e aprendizagem pautado numa pesquisa-ação impulsiona transformações nas ações e nas interações dos participantes. Com isso, nos embrenhamos numa seara intimamente ligada com a prática docente sem deixar de lado os estudos teóricos para reformar o pensamento/ação sobre o ensinar a aprender computação. No processo da pesquisa-ação foi realizado um planejamento colaborativo, o desenvolvimento das ações, observações e relatos de experiência e novas reflexões e compreensões.

\section{Constituição do CDC: ações e reflexões no ensino da computação}

Para o desenvolvimento das atividades, os licenciandos estudaram o conteúdo específico da área de referência ao selecionarem materiais, na internet, em livros, artigos, blogs, vídeos, criando um projeto integrador por meio do planejamento colaborativo. Cambraia e Zanon (2018) chamam atenção para a necessidade de construir uma "linguagem comum" por meio do planejamento colaborativo, de forma a proporcionar a constituição de uma comunidade "viva" na formação de professores, vinculada com os problemas do mundo e possibilitando a constituição de professores crítico-reflexivos. Nesse sentido, os licenciandos planejaram e desenvolveram atividades de computação desplugada para uma turma de alunos do Proeja.

Dentre as atividades planejadas está o "jogo das laranjas", em que a finalidade é ensinar o funcionamento da rede mundial de computadores, destacando o papel dos roteadores e a ocorrência de bloqueios na rede (deadlock) com trabalho interdisciplinar com a Matemática e Educação Física. Assim, aprofundaram a temática e prepararam o jogo de forma a relacionar a atividade lúdica com o conhecimento da computação. No planejamento da atividade, foi destacado o ensino da Computação na Educação Básica como fundamental e o desenvolvimento do "raciocínio lógico e a resolução coletiva de problemas" (RF, p. 6).

O material didático, produzido levou em consideração a possibilidade de que os alunos pudessem manipular objetos para construir o aprendizado. Os jogos foram construídos com EVA, cartões de papel e fotocópias, privilegiando a construção do conhecimento da computação na Educação Básica de forma interdisciplinar, pois

\footnotetext{
${ }^{7}$ Os detalhes do jogo são encontrados no livro "Computer Science - ensinando Ciência da Computação sem o uso dos computadores" referenciado neste texto. Os alunos selecionaram um vídeo para ampliar a compreensão da temática pelos alunos: https://www.youtube.com/watch?v=Iqcp3k8DgGw.
} 
VIII Congresso Brasileiro de Informática na Educação (CBIE 2019)

Anais dos Workshops do VIII Congresso Brasileiro de Informática na Educação (WCBIE 2019)

abrangeu conceitos de Matemática, Português, Educação Física, Estudos Sociais e Geografia.

A organização do material didático e das atividades permitiu aos futuros professores pesquisar diferentes metodologias, que exigiam um maior domínio de conceitos, maior autonomia e trabalho colaborativo. A formação de diferentes estilos de ensinar e aprender depende dos conteúdos e dos objetivos definidos em cada atividade. Diferentes olhares para o conteúdo e o modo de ensinar constituem o CDC, como pode ser visualizado na produção do material didático e na organização para discussão dos conceitos em questão.

$\mathrm{Na}$ atividade - "Sistemas numéricos - formando números binários", os licenciandos fazem uma exposição explicando os sistemas de numeração binário e decimal. O material didático foi criado para possibilitar a manipulação dos materiais pelos alunos (material desenvolvido durante as aulas de Metodologia do Ensino da Computação $\mathrm{I}^{8}$ ) e utilizado no componente curricular de PEC IV para planejar, desenvolver as ações. Explicaram a atividade aos alunos utilizando o material, potencializando conceitos matemáticos e conversão de numeração decimal para binária e vice-versa. Posteriormente, os alunos manipularam os cartões e fizeram conversões entre os diferentes sistemas de numeração. Na conclusão da atividade conseguiam converter números de decimal para binário e vice-versa, trazendo indícios de que o planejamento colaborativo e a estratégia de ensino utilizada possibilitaram a compreensão do conhecimento da computação (linguagem de máquina - sistemas de numeração) e conceitos matemáticos (numeração decimal, soma, subtração, exponenciação e conversões entre sistemas de numeração) pelos alunos.

A atividade de detecção e correção de erros pode ser desenvolvida em conjunto com a Matemática. Os quadrados, inicialmente, são dispostos numa matriz $5 \mathrm{X} 5$, distribuindo as cores aleatoriamente (cartões de duas cores - vermelhos e pretos sugerimos pedir para os alunos arrumar os quadrados). Depois, colocamos uma sexta fileira de cartões, obtendo uma matriz 6X6. Um dos licenciandos sai da sala para não visualizar as modificações na matriz (alguém que conhece o método). Na sala viramos uma carta qualquer (dificilmente, alguém consegue saber qual carta foi virada). O licenciando retorna para a sala e perguntamos: "Qual carta foi virada?". Ele acerta, pois usa o seguinte método: ao colocar a sexta fileira põe o cartão com a respectiva cor para deixar números pares em ambas as cores. Por exemplo, se tiver três cartas vermelhas e duas pretas, colocará uma vermelha. Para adivinhar a carta que foi virada basta verificar em qual coluna e linha o número de cores é ímpar. Os alunos ficaram motivados e interessados em saber como foi "adivinhado", ou seja, provocamos a curiosidade e depois explicamos os conceitos e o processo de correção e detecção de erros, de forma que cada aluno conseguiu compreender o jogo e entender os conceitos da computação vinculados à atividade. Nesse processo não fornecemos as respostas de imediato, primeiro proporcionamos a compreensão dos conceitos para depois explicar o método de descobrir a carta.

\footnotetext{
${ }^{8}$ Além de utilizarmos materiais do livro Ciência da Computação sem computadores, os licenciandos são desafiados a criarem seus próprios exercícios. Interessantes experiências têm se sobressaído nas aulas de Metodologia do Ensino da Computação I que precisam ser desenvolvidas e documentadas para proporcionar reflexões que potencializem o ensino da computação.
} 
VIII Congresso Brasileiro de Informática na Educação (CBIE 2019)

Anais dos Workshops do VIII Congresso Brasileiro de Informática na Educação (WCBIE 2019)

Das nove atividades planejadas foram trabalhadas apenas cinco: Sistemas numéricos; Jogo de Boole; Pintando pixels; Detecção e correção de erros. "Aprendemos a fazer planejamentos da aula e que, [...], o planejado pode ser modificado durante a aula" (Licenciando 5), essa constatação é indício de produção de saberes docentes pelo futuro professor.

No RF destacaram que "como foi a primeira experiência desenvolvida se preferiu ter mais conteúdo do que ficar sem fazer nada durante a aula" (p.20). A quinta e última atividade desenvolvida foi "batalha naval", pois o tempo disponível em sala de aula se adequava para realizar a conclusão e executar o jogo lógico novamente. Geralmente, um professor com mais experiência prioriza várias formas de planejamento, pois, geralmente, aproveita as atividades para exemplificar e problematizar, possibilitando "navegar por mares mais profundos", construindo conhecimentos significativos nas interações produzidas. Os professores experientes se distinguem dos menos experientes pelo fato de "planejarem a partir de planos incompletos, de imagens de aulas baseadas na experiência anterior, e de se preocuparem muito mais com o fluxo de atividades para uma semana inteira do que com os mínimos detalhes de cada aula [Gauthier 2013, p. 199].

Assim, se priorizou atividades que relacionavam conhecimento da computação com questões do dia a dia: funcionamento da internet; linguagem de máquina (celulares, smartphones, computadores) propiciando o entendimento de que a tecnologia é uma construção humana, proporcionando a integração de diferentes disciplinas. Na PEC IV são articuladas disciplinas de diferentes semestres da LC, que propiciam pensar que o movimento interdisciplinar supera a ideia de que mais professores precisam trabalhar ao mesmo tempo ou que precise reunir ao mesmo tempo determinadas disciplinas. $\mathrm{O}$ aluno faz o movimento interdisciplinar ao relacionar os conteúdos com a realidade como uma totalidade complexa.

O projeto integrador realizado proporcionou a percepção de que os licenciandos são sujeitos de sua própria formação. Não se trata apenas de desenvolver uma atividade em sala de aula, o objetivo foi entender a viabilidade de desenvolver atividades que trabalham conceitos complexos da computação na Educação Básica e desenvolver o raciocínio lógico dos alunos participantes. Mesmo que o jogo lógico não seja um teste eficaz para essa situação, proporcionou um desafio ao coletivo de futuros professores e alunos, e, mais empenho e envolvimento dos mesmos, pois "a pesquisa e a aplicação dos testes aproximaram com a realidade". (Licenciando 4). A realidade referida é a interação com o espaço da escola, com os alunos, planos de aula, documentos e gestão do processo de aprendizagem na formação de professores. Assim, por meio "da pesquisa consegui ter uma boa ideia de como é ser professor. Essa experiência só veio a contribuir com meus conhecimentos" (Licenciando 5). Demonstrando que o desafio da pesquisa proporciona a construção do CDC.

Como criaram um questionário para os alunos possibilitou aos licenciandos realizar uma avaliação sobre a importância do conhecimento da computação pela concepção dos alunos.

Ao serem questionados sobre a importância do conhecimento da computação na escola o Aluno 3 [nos excertos retirados do relatório final aparece a terminologia Aluno para se referenciar aos alunos Proeja] afirma que "foi uma aula muito produtiva em termos do desenvolvimento do raciocínio lógico" e "é um conhecimento que se usa em todas as áreas" (Aluno 5). Já o 
VIII Congresso Brasileiro de Informática na Educação (CBIE 2019)

Anais dos Workshops do VIII Congresso Brasileiro de Informática na Educação (WCBIE 2019)

\begin{abstract}
Aluno 4 afirmou que se trata de uma "forma diferente de ver as coisas" e que "poderia ter mais aulas como essa". Os excertos nos mostram a importância da computação para o desenvolvimento de um olhar interpretativo para o mundo e, ao mesmo tempo, possibilitando o desenvolvimento do raciocínio lógico. Ainda destacam a importância de ter mais aula como essa no PROEJA (RF, p. 21).
\end{abstract}

Foi perceptível que a participação, valorização e envolvimento dos alunos, nas atividades, fez com que os licenciandos tivessem uma maior motivação com o trabalho desenvolvido. Conforme Licenciando 3: "os alunos estavam visivelmente empolgados com os conteúdos e contentes pela aula diferenciada". Entendo que essa valorização é possível pela criação de atividades desafiadoras e metodologias criativas, que relacionam os conteúdos escolares com a realidade como uma totalidade complexa.

A avaliação do componente curricular não ocorreu por meio de provas. Avaliamos os licenciandos pela criatividade na criação do material didático, 0 planejamento das atividades de computação desplugada, o desenvolvimento das atividades no Proeja, o RF e o seminário integrador - o relatório das ações foi apresentado para todas as turmas da LC - proporcionando a realização do ciclo dialético da pesquisa [Moraes e Valderez 2002]. Foi um momento de muito aprendizado para os licenciandos e também para os professores formadores, que ficou perceptível uma maior valorização do trabalho desenvolvido na disciplina e no componente curricular, algo importante para o pensar/fazer educação e para o reconhecimento profissional docente. Portanto, de acordo com Shulman (1986), o professor não só domina o procedimento, mas também o conteúdo e o fundamento lógico e explica porque ensina determinado conteúdo, sempre valorizando a participação do aluno como sujeito na elaboração do conhecimento. A interação com o espaço da escola foi uma das formas de vivenciar a importância e o significado do Ensino da Computação na Educação Básica.

\title{
3. Considerações para continuidade das espirais reflexivas
}

As reflexões na PEC IV, foram produzidas a partir da pesquisa como princípio educativo, instituíram uma pesquisa-formação-ação, que proporcionou $o$ desenvolvimento da autonomia e autoria no processo formativo, refletidas no planejamento colaborativo, estudos, elaboração de atividades, organização e desenvolvimento das ações como experiência formativa. Nesse sentido, destacamos ações/reflexões que são indícios da construção do CDC: - Interação dos cursos de Formação de Professores com Escola de Educação Básica com interlocução entre professores formadores, professores e alunos da Educação Básica e licenciandos. Compreensão do conhecimento do conteúdo com profundidade para desenvolver metodologias criativas e interdisciplinares. - Priorizar várias formas de planejamento, dentre os quais, o planejamento colaborativo como um processo reflexivo para criar desafios que envolvam os alunos e alcançar objetivos. - Transformar conhecimentos científicos em conhecimentos escolares. - Produção de materiais didáticos levando em conta as características dos alunos. - Escrita reflexiva para produzir conhecimentos científicos (produzido pela escrita de artigo como este).

Com o exposto novas questões foram tematizadas e provocaram outras buscas e compreensões constituindo o CDC, que compreende o ensino como um processo de compreensão e raciocínio, transformação e reflexão, que envolve o conhecimento com 
VIII Congresso Brasileiro de Informática na Educação (CBIE 2019)

Anais dos Workshops do VIII Congresso Brasileiro de Informática na Educação (WCBIE 2019)

profundidade dos conteúdos, mas também uma educação humanista abrangente para reconstruir as aprendizagens. Assim, convidamos os leitores para instituir e vivenciar processos de pesquisa-ação para reconstruir a formação de professores de computação.

\section{Referências}

Bell, T., Witten, I. H. e Fellows, M. (2011), "Computer Science Unplugged - Ensinando Ciência da Computação sem o uso dos computadores", https://classic.csunplugged.org/wp-content/uploads/2014/12/CSUnpluggedTeachersportuguese-brazil-feb-2011.pdf, August.

Cambraia, A. C. e Zanon, L. B. (2018), Desenvolvimento Profissional Docente em uma Licenciatura: interlocuções sobre o projeto integrador. Revista Brasileira de Educação. V. 23, Rio de Janeiro, http://dx.doi.org/10.1590/s1413-24782018230043.

Carr, W. e Kemmis, S. (1988), Teoria crítica de la enseñanza: investigación-acción en la formación del profesorado, Barcelona, Martinez Roca, $1^{\text {a }}$ edição.

França, R. S., Silva, W. C., Amaral, H. J. C. (2012). Ensino de Ciência da Computação na Educação Básica: Experiências, Desafios e Possibilidades. XXXII Congresso da Sociedade Brasileira de Computação - XX Workshop sobre Educação em Computação (WEI).

Gauthier, C., Martineau, S., Desbiens, J. F., Malo, A., Simard, D. (2013), Por uma teoria da Pedagogia: pesquisas contemporâneas sobre o saber docente, Ijuí, Ed. UNIJUÍ, $3^{\text {a }}$ edição.

Leal Castro, A. (2014), El Conocimiento Didáctico del Contenido (CDC): una herramienta que contribuye en la configuración de la identidad profesional del professor, In Magistro, p. 89-110.

Libâneo, J. C. (2015), Formação de professores e didática para o desenvolvimento humano, In Revista Educação e Realidade, p. 629-650.

Lopes, A. C. (2007), Currículo e Epistemologia, Ijuí, Ed. UNIJUÍ, $1^{\text {a }}$ edição.

Lopes, C. S. (2009), O conhecimento pedagógico do conteúdo e os processos de formação do professor de Geografia, Porto Alegre, ENPEG, $10^{a}$ edição.

Moraes, R. e Valderez, M. R. L. (2002), Pesquisa em sala de aula: tendências para educação em novos tempos, Porto Alegre, EDIPUCRS, $1^{a}$ edição.

Moraes, R. e Galiazzi, M. C. (2013), Análise Textual Discursiva. 2. Ed. Ijuí: Ed. Unijuí.

Padilha, R. P. (2001), Planejamento dialógico: como construir o projeto políticopedagógico da escola, São Paulo, Cortez, $1^{\mathrm{a}}$ edição.

Shulman, L. S. (1986), Those who understand: knowledge growth in teaching. In Educational Researcher, p. 4-14.

Shulman, L. S. (1987), Knowledge and teaching: foundations of new reform. In Harvard Educational Review, p. 1-22.

Shulman, L. S. (2014), Conhecimento e ensino: fundamentos para a nova reforma. In Cadernos Cenpec, p. 196-229. 